\title{
Orange-Brown Precipitate: A Threat to the Success of Endodontic Treatment - An In Vitro Study
}

\author{
Shashidhar Chandrashekhar ${ }^{1 *}$, Dinesh Rao ${ }^{2}$, Jyothi Shashidhar $^{3}$, Smitha Naik $^{4}$ \\ ${ }^{1}$ Department of Conservative Dentistry and Endodontics, SMBT Dental College and Hospital, PhD Scholar, Pacific Dental \\ College, Udaipur, Rajasthan-313024, India; ${ }^{2}$ Department of Pediatric Dentistry, Pacific Dental College and Hospital, Udaipur, \\ Rajasthan-313024, India; ${ }^{3}$ Department of Pediatric Dentistry, SMBT Dental College and Hospital, Sanagmner-422608, India; \\ ${ }^{4}$ Department of Oral and Maxillofacial Pathology, Pacific Dental College and Hospital, Udaipur, Rajasthan-313024, India
}

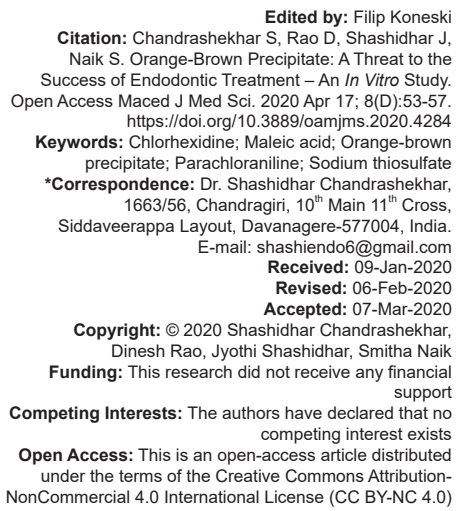

\begin{abstract}
AIM: The aim of the present study was to evaluate the effect of various intermediate irrigating solutions in the removal of orange-brown precipitate formed due to alternative use of sodium hypochlorite $(\mathrm{NaOCl})$ and chlorhexidine $(\mathrm{CHX})$ root canal irrigants.

METHODS: The root canals of 50 mandibular premolars were prepared using ProTaper Universal Rotary instruments (Dentsply Maillefer, Ballaigues, Switzerland) up to size F3. The roots were randomly divided into five experimenta groups specified by the intermediate irrigant used; Group 1: No intermediate irrigant used (control), Group 2: Saline, Group 3: $7 \%$ maleic acid (MA), Group 4: $4 \%$ sodium thiosulfate, and Group 5: $70 \%$ isopropyl alcohol $(n=10)$. After final irrigation with $\mathrm{CHX}$, the specimens were evaluated for the presence/absence of orange-brown precipitate under stereomicroscope.

RESULTS: Mean precipitate for all experimental groups was calculated using ANOVA F test which showed orangebrown precipitate (parachloroanaline) in all groups except Group 4 and Group 5 which were highly significant $(p<0.001)$ at all the levels of root canal. Intergroup pairwise comparison was done using Tukey's post hoc test.

CONCLUSION: About 7\% MA is effective in minimizing the formation of orange-brown precipitate when used as intermediate irrigant between $\mathrm{NaOCl}$ and $\mathrm{CHX}$. However, the precipitate was not observed with $4 \%$ sodium thiosulfate and $70 \%$ isopropyl alcohol.
\end{abstract}

\section{Introduction}

The main objective of endodontic therapy is the complete removal of microorganisms from the root canal system. Mechanical instrumentation alone cannot completely eliminate microbes from the complex root canal system. Irrigants are recommended along with instrumentation to completely disinfect the root canal system [1].

Sodium hypochlorite $(\mathrm{NaOCl})$ is used as the irrigant of first choice during root canal therapy due to its excellent antimicrobial properties and tissue dissolving potential [2].

In retreatment cases, the use of broad-spectrum antimicrobial solution, chlorhexidine $(\mathrm{CHX})$ gluconate, is recommended as an adjunct or alternative to $\mathrm{NaOCl}$ due to its lesser toxicity [3] and antimicrobial substantivity [4]. It is also seen that the alternate use of $\mathrm{NaOCl}$ and $\mathrm{CHX}$ is to take advantage of the beneficial qualities of both $\mathrm{NaoCl}$ as well as $\mathrm{CHX}$ solutions [5].

When both $\mathrm{NaOCl}$ and $\mathrm{CHX}$ solutions are used alternatively as root canal irrigants, resulted in the formation of orange-brown precipitate, known as parachloroaniline; which is possibly carcinogenic to humans and has immune-toxic effects [6], [7]. Proper sealing of obturating material to canal walls is also hampered due to the orange-brown precipitate occluding the dentinal tubules [7].

Hence, many studies are being carried out to use intermediate intracanal solutions to eliminate the residual $\mathrm{NaOCl}$ before using $\mathrm{CHX}$ to prevent the formation of a precipitate [6], [7], [8], [9].

Sodium thiosulfate has been used as an antidote to cyanide poisoning [10] and in the treatment of calciphylaxis in hemodialysis patients with end-stage kidney disease [11]. It has also been effectively used for neutralizing $\mathrm{NaOCl}$ in the laboratory studies [12].

Various solutions such as distilled water, isopropyl alcohol, $50 \%$ citric acid, and $7 \%$ maleic acid (MA) are used as intermediate intracanal flush to nullify or eliminate $\mathrm{NaOCl}$ from the root canal before $\mathrm{CHX}$ is used to prevent orange-brown precipitate [13], [14].

Hence, this in vitro study was done to evaluate the effect of various intermediate irrigating solutions in the prevention of orange-brown precipitate formed due to alternative use of $\mathrm{NaOCl}$ and $\mathrm{CHX}$ root canal irrigants 
with the null hypothesis that there is no significant difference among the tested irrigants in the prevention of orange-brown precipitate.

\section{Methodology}

The sample size was calculated using statistical product and service solution (SPSS) version 21 for Windows (SPSS Inc., Chicago, IL). Descriptive quantitative data were expressed in proportion (percentage). Confidence interval is set at $95 \%$ and probability of alpha error set at $5 \%$. Power of the study is set at $80 \%$. The sample size was calculated with a total of 50 teeth which were further divided into five groups, 10 in each group.

Teeth which were free of caries, restoration, visible cracks, or other structural defects were included in the study and teeth with developmental anomalies, trauma dehydrated (brittle), and calcified canals were excluded from our study.

Fifty human permanent, intact, and mature maxillary anterior teeth with single canal, recently extracted were selected. After washing with distilled water and ultrasonic scaling, the specimens were immersed in $0.5 \%$ Chloramine $\mathrm{T}$ solution until use. The teeth were decoronated to obtain a standardized root length of $10 \mathrm{~mm}$. Canal patency was evaluated using \#10K file and teeth with canal obstructions were discarded. The actual length of each tooth was determined with \#10K file, which was introduced into the canal until its tip emerged through the major apical foramen. The working length was established by subtracting $1 \mathrm{~mm}$ from the actual length. The apices of the specimens were sealed with wax to prevent extrusion of irrigating solutions. All the canals were prepared by the same operator using rotary ProTaper files (Dentsply Maillefer, Ballaigues, Switzerland) until F3 size. The canals were irrigated with $3 \% \mathrm{NaOCl}$ between each instrumentation sequence. After complete mechanical instrumentation, all the samples were thoroughly flushed with $2.5 \mathrm{ml}$ of $3 \% \mathrm{NaOCl}$. The samples were randomly allocated to five groups of 10 samples each based on the use of $2.5 \mathrm{ml}$ of intermediate irrigating solution for $60 \mathrm{~s}$ :

Group 1 - No intermediary intracanal irrigant used (control group); Group 2 - Saline, Group 3 - 7\% MA, Group 4 - 4\% sodium thiosulfate, and Group 5 $70 \%$ isopropyl alcohol. After that, all the group samples were irrigated with $2.5 \mathrm{ml}$ of $2 \% \mathrm{CHX}$ gluconate solution as final wash.

The root canals were dried using paper points of corresponding apical preparation size. Two longitudinal grooves were made along the buccal and lingual surfaces of the roots with water-cooled diamond disc. The roots were then sectioned using mallet and chisel.
The exposed surfaces of the root canal were examined for the orange-brown precipitate using stereomicroscope (MAGNUS MS 24, India) at $\times 10$. The images were then transferred to a computer and evaluated.

Root samples of each group were examined at the coronal, middle, and apical third levels. The thickness of the precipitate was measured from its outer surface to the inner dentinal wall at a uniplanar level using Image Analysis System, Chroma System Pvt. Ltd., India.

\section{Results}

Overall intergroup comparison among tested irrigants for mean thickness of precipitate was done using ANOVA F test followed by Tukey's post hoc to find intergroup pairwise multiple comparison between groups.

Although the precipitate was concentrated at all the level of the root canal, it was more significant at coronal and middle thirds followed by the apical third of the canals (Figure 1).

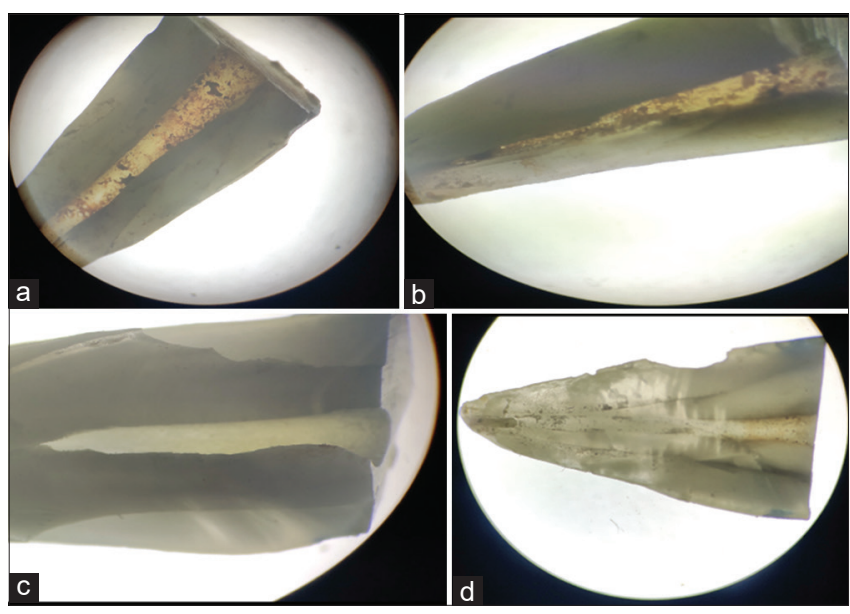

Figure 1: Images of samples observed under stereomicroscope $(\times 10)$ (a) Group 1 - control, (b) Group 2 - saline, (c) Group 3 - maleic acid $7 \%$, (d) Group 4-4\% sodium thiosulfate, (e) Group 5-70\% isopropyl alcohol

The mean thickness of the precipitate was maximum at the coronal, middle thirds, and minimum at the apical levels for all groups (Table 1 and Graph 1).

Table 1: Comparative statistics of mean precipitate in microns

\begin{tabular}{llll}
\hline Groups & Cervical mean (SD) & Middle mean (SD) & Apical mean (SD) \\
\hline Group 1 & $889.9(15.23)$ & $422.3(8.53)$ & $250.0(21.5)$ \\
Group 2 & $383.3(30.75)$ & $252.6(21.55)$ & $71.42(5.53)$ \\
Group 3 & $124.3(13.53)$ & $70.59(9.49)$ & $22.4(2.67)$ \\
ANOVA F test & $\mathrm{F}=4012.0$ & $\mathrm{~F}=1774.3$ & $\mathrm{~F}=1033.3$ \\
p value, significance & $\mathrm{p}<0.001^{* *}$ & $\mathrm{p}<0.001^{* *}$ & $\mathrm{p}<0.001^{* *}$ \\
\hline
\end{tabular}

There was a statistically significant difference in the thickness of the precipitate formed by Group 1, Group 2, and Group 3 ( $p<0.001$ ). Intergroup pairwise comparison showed that the thickness of the precipitate was more in Group 1 compared to Group 2 and Group 3 at all the three levels which were statistically significant $(p<0.001)$ (Table 2). 


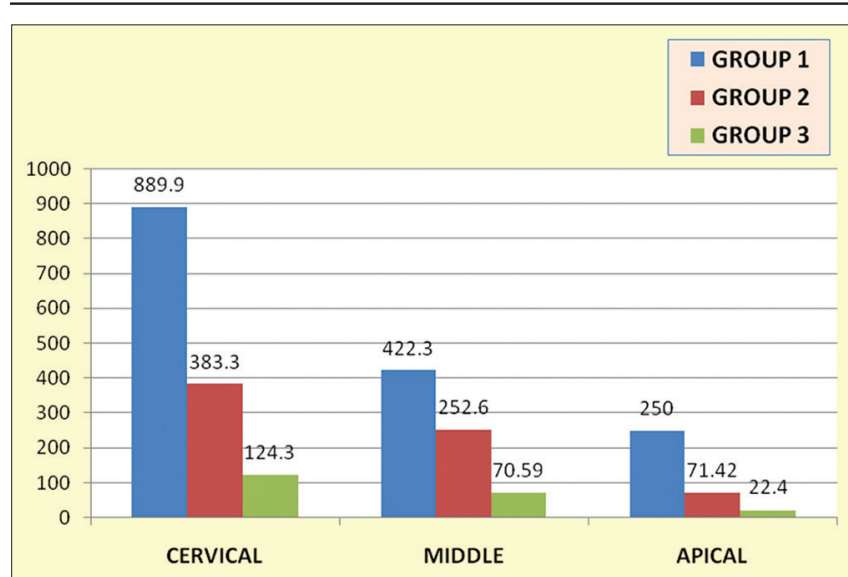

Graph 1: Mean of precipitate in Group 1, Group 2, and Group 3 (in micron)

Table 2: Tukey's post hoc test to find pairwise multiple comparison

\begin{tabular}{llll}
\hline Group 1 versus Group 2 & $\mathrm{p}<0.001^{* *}$ & $\mathrm{p}<0.001^{* *}$ & $\mathrm{p}<0.001^{* *}$ \\
Group 1 versus Group 3 & $\mathrm{p}<0.001^{* *}$ & $\mathrm{p}<0.001^{* *}$ & $\mathrm{p}<0.001^{* *}$
\end{tabular}
Group 2 versus Group $3 \quad p<0.001^{* *} \quad p<0.001^{* *} \quad p<0.001^{* *}$

$p>0.05$ - no significant difference, ${ }^{*} p<0.05$ - significant, ${ }^{* *} p<0.001$ - highly significant.

There was no precipitate formed in Group 4 and Group 5.

\section{Discussion}

Root canal irrigants play an important role in eliminating microorganisms from the root canals which otherwise are difficult to remove with biomechanical preparation alone [1]. Hence, irrigants are used alone or in combination to achieve better antimicrobial effect. Many studies have reported that the combination of irrigants resulted in negative effect on the outcome of root canal therapy [5], [15]. This could be due to the formation of byproducts which are cytotoxic and interferes with the adaptation of sealers to root canal wall [16].

In the present study, emphasis is given to the orange brown, discolored precipitate formed by the interaction of $\mathrm{NaOCl}$ and $\mathrm{CHX}$.

In our study, in Group 1, wherein no intermediate irrigants were used showed the presence of orangebrown precipitate at all the levels of root canals with the mean thickness of $889.9 \mu$ (cervical), $422.3 \mu$ (middle), and $250 \mu$ in the apical third of root canal. The orangebrown color of the precipitate occurs when $\mathrm{CHX}$ gets hydrolyzed into smaller fragments, due to breakage of the bond between carbon and nitrogen, forming a by-product parachloroanaline (PCA) [16].

It has been established that PCA is toxic; as an aromatic amine, the primary toxic effect is methemoglobin formation. In the root canal system, this precipitate, if formed, occludes the dentinal tubules and prevents sealer penetration leading to its poor bond strength [7], [16].
As $\mathrm{CHX}$ is a dicationic acid $(\mathrm{pH}: 5.5-6.0)$ donates protons which are accepted by the basic $\mathrm{NaOCl}$ resulting in formation of insoluble neutral precipitate [6] which acts as a chemical smear layer and compromises the dentin permeability by occluding them in the coronal and middle thirds of the canal [7]. It affects the diffusion of intracanal medication. An additional interface between the sealer and the dentin also affects the obturation seal, especially with resin sealers, in which a hybrid layer is required [16]. Removing $\mathrm{NaOCl}$ by aspiration and paper points showed no significant reduction in precipitate formation as dentin and its tubules harbor enough residual $\mathrm{NaOCl}$ to react with the $\mathrm{CHX}$, raising potential concerns [7]. Basrani et al. concluded that the formation and amount of PCA is directly related to the concentration of $\mathrm{NaOCl}$, with $0.023 \%$ being the lowest concentration at which color change was observed and $0.19 \%$ minimum at which the precipitate formed [6].

Earlier studies have demonstrated the formation of precipitate by gas chromatography-mass spectrometry (MS), X-ray photon spectroscopy (XPS), and time-of-flight secondary ion MS (TOF-SIMS). TOFSIMS was used to determine the presence of PCA, but the amount was determined with the help of XPS [17].

Hence, intermediate irrigants are tried to completely remove or deactivate $\mathrm{NaOCl}$ in the root canal before other irrigants are used as final rinse.

In Group 2, wherein saline was used as intermediate irrigant also showed orange-brown precipitate which was significantly less $(p<0.001)$ compared to Group 1 at all the levels of root canal. The mean thickness of the precipitate was found to be $383.3 \mu$ (cervical), $252.6 \mu$ (middle), and 71.42 $\mu$ (apical third) of the root canal. This finding is in agreement with the previous study, wherein authors used an intermediate irrigant after $\mathrm{NaOCl}$ and before CHX such as saline, $50 \%$ citric acid, and 14\% EDTA, to prevent the formation of PCA, but none of those prevented it [18].

In Group 3, wherein 7\% MA was used as an intermediate irrigant showed sparse orange-brown precipitate which was significantly less $(p<0.001)$ when compared to Group 1 and Group 2 at all the levels of the root canal but could not completely eliminate its formation. The mean thickness of precipitate was found to be $124.3 \mu$ (cervical), $70.59 \mu$ (middle), and 22.4 (apical third) of root canal.

MA is used as a conditioner in dental adhesives [19]. For smear layer removal, it has been shown that $7 \%$ MA is significantly better than $17 \%$ EDTA [20]. Furthermore, 7\% MA is less cytotoxic comparing $17 \%$ EDTA [21], [22]. A study was conducted to evaluate the interaction between $\mathrm{MA}$ and $\mathrm{CHX}$ by high-performance liquid chromatography and to evaluate the available chlorine content in $\mathrm{NaOCl}$ by the standard iodine/thiosulfate titration method. The authors concluded that there were no adverse interactions or 
precipitate formation observed when MA was combined with $\mathrm{CHX}$, but the available chlorine content was reduced when $\mathrm{NaOCl}$ was mixed with MA [23]. Hence, MA as intermediate irrigant is one option to reduce the formation of orange-brown precipitate.

In Group 4, wherein 70\% isopropyl alcohol was used showed no precipitate in any of the sample. Isopropyl alcohol as an intermediate rinse between $\mathrm{NaOCl}$ and $\mathrm{CHX}$ has been employed to prevent the formation of the precipitate as it is volatile, tensioactive, and highly electronegative and can penetrate deep to remove the residual $\mathrm{NaOCl}$ from the canals. The findings of our study are in agreement with the previous studies [8] which concluded that isopropyl alcohol resulted in completely clean canals, whereas the use of saline or distilled water produced a sparse precipitate. The precipitate was present mainly in the coronal and middle thirds of the canals.

In Group 5, wherein 4\% sodium thiosulfate was used as an intermediate irrigant showed no precipitate in any of the sample showed no precipitate in any of the sample.

The reduction in the formation of orange-brown precipitate in Group $5(\mathrm{NaOCl}+$ sodium thiosulfate $+\mathrm{CHX})$ may be attributed to sodium thiosulfate's neutralizing action against $\mathrm{NaOCl}$ which is in accordance with the study conducted by Radcliffe et al. where $1.93 \%$ sodium thiosulfate was found to be effective in neutralizing $0.5 \% \mathrm{NaOCl}$ and $3.86 \%$ successfully neutralized the concentrations $>1.0 \% \mathrm{NaOCl}$ [12]. Therefore, the intermediate flushes play an important role in preventing the formation of orange-brown precipitate due to alternate use of $\mathrm{NaOCl}$ and $\mathrm{CHX}$.

Finally, if the flocculate is formed, then acetic acid can be used to dissolve the precipitate [24].

Few studies replaced $\mathrm{CHX}$ with QMix and the mixture of $\mathrm{QMix}^{\mathrm{TM}}$ and $\mathrm{NaOCl}$ did not result in parachloroaniline formation [9].

Other strategies to prevent the formation of orange-brown precipitate are to use of alexidine instead of $\mathrm{CHX}$ which has better antibacterial action sequentially or in combination with $\mathrm{NaOCl}$ irrigation which saves time and additional step of using intermediate flushes [25].

\section{Conclusion}

Within the limitations of the present study:

1. An orange-brown precipitate was formed at all the levels of root canal when chlorhexidine irrigant was used after $\mathrm{NaOCl}$

2. The precipitate was more in the cervical third when compared to middle and apical third which was statistically significant

3. Saline and $7 \%$ MA used as intermediate irrigant minimized the formation of orange-brown precipitate but could not completely eliminate it.

4. Isopropyl alcohol and sodium thiosulfate could able to completely eliminate orange-brown precipitate when used as intermediate irrigant between $\mathrm{NaOCl}$ and chlorhexidine.

\section{References}

1. Byström A, Sundqvist G. Bacteriologic evaluation of the efficacy of mechanical root canal instrumentation in endodontic therapy. Scand J Dent Res. 1981;89(4):321-8. https://doi. org/10.1111/j.1600-0722.1981.tb01689.x PMid:6947391

2. Estrela C, Estrela CR, Barbin EL, Spanó JC, Marchesan MA, Pécora JD. Mechanism of action of sodium hypochlorite. Braz Dent J. 2002;13(2):113-7. https://doi.org/10.1590/ s0103-64402002000200007

PMid:12238801

3. Leonardo MR, Tanomaru Filho M, Silva LA, Nelson Filho P, Bonifácio $\mathrm{KC}$, Ito IY. In vivo antimicrobial activity of $2 \%$ chlorhexidine used as a root canal irrigating solution. J Endod. 1999;25(3):167-71. https://doi.org/10.1016/ s0099-2399(99)80135-6

PMid:10321180

4. Okino LA, Siqueira EL, Santos $M$, Bombana AC, Figueiredo JA. Dissolution of pulp tissue by aqueous solution of chlorhexidine digluconate and chlorhexidine digluconate gel. Int Endod J. 2004;37(1):38-41. https://doi. org/10.1111/j.1365-2591.2004.00749.x

PMid: 14718055

5. Zehnder M. Root canal irrigants. J Endod. 2006;32(5):389-98 PMid:16631834

6. Basrani BR, Manek S, Sodhi RN, Fillery E, Manzur A. Interaction between sodium hypochlorite and chlorhexidine gluconate. J Endod. 2007;33(8):966-9. https://doi.org/10.1016/j. joen.2007.04.001

PMid: 17878084

7. Bui TB, Baumgartner JC, Mitchell JC. Evaluation of the interaction between sodium hypochlorite and chlorhexidine gluconate and its effect on root dentin. J Endod. 2008;34(2):181-5. https://doi. org/10.1016/j.joen.2007.11.006

PMid: 18215677

8. Krishnamurthy S, Sudhakaran S. Evaluation and prevention of the precipitate formed on interaction between sodium hypochlorite and chlorhexidine. J Endod. 2010;36(7):1154-7. https://doi.org/10.1016/j.joen.2010.01.012

PMid:20630289

9. Arslan H, Uygun AD, Keskin A, Karatas E, Seçkin F, Yıldırım A. Evaluation of orange-brown precipitate formed in root canals after irrigation with chlorhexidine and QMix and spectroscopic analysis of precipitates produced by a mixture of chlorhexidine/ $\mathrm{NaOCl}$ and QMix/NaOCl. Int Endod J. 2015;48(12):1199-203. https://doi.org/10.1111/iej.12427 PMid:25557836

10. Baskin SI, Horowitz AM, Nealley EW. The antidotal action of sodium nitrite and sodium thiosulfate against cyanide poisoning. J Clin Pharmacol. 1992;32(4):368-75. https://doi. org/10.1002/j.1552-4604.1992.tb03849.x

PMid:1569239 
11. Auriemma M, Carbone A, Di Liberato L, Cupaiolo A, Caponio C, De Simone C, et al. Treatment of cutaneous calciphylaxis with sodium thiosulfate: Two case reports and a review of the literature. Am J Clin Dermatol. 2011;12(5):339-46. https://doi. org/10.2165/11587060-000000000-00000

PMid:21834598

12. Radcliffe CE, Potouridou L, Qureshi R, Habahbeh N, Qualtrough A, Worthington $\mathrm{H}$, et al. Antimicrobial activity of varying concentrations of sodium hypochlorite on the endodontic microorganisms Actinomyces israelii, A. naeslundii, Candida albicans and Enterococcus faecalis. Int Endod J. 2004;37(7):43846. https://doi.org/10.1111/j.1365-2591.2004.00752.x PMid: 15189432

13. Khadse P, Kamra A, Banga KS. Effectiveness of various intermediate irrigants for the prevention of precipitate formed by the interaction of sodium hypochlorite and chlorhexidine an in vitro study. Endodontology. 2014;26(2):309-13.

14. Arslan H, Gok T, Saygili G, Altintop H, Akçay M, Çapar ID. Evaluation of effectiveness of various irrigating solutions on removal of calcium hydroxide mixed with $2 \%$ chlorhexidine gel and detection of orange-brown precipitate after removal. J Endod. 2014;40(11):1820-3. https://doi.org/10.1016/j. joen.2014.06.003

PMid:25201644

15. Kuruvilla JR, Kamath MP. Antimicrobial activity of $2.5 \%$ sodium hypochlorite and $0.2 \%$ chlorhexidine gluconate separately and combined, as endodontic irrigants. J Endod. 1998;24(7):472-6. https://doi.org/10.1016/s0099-2399(98)80049-6

PMid:9693573

16. Gupta H, Kandaswamy D, Manchanda SK, Shourie S. Evaluation of the sealing ability of two sealers after using chlorhexidine as a final irrigant: An in vitro study J Conserv Dent. 2013;16(1):75-78. https://doi.org/10.4103/0972-0707.105304

17. Kim HS, Zhu Q, Baek SH, Jung IY, Son WJ, Chang SW, et al. Chemical interaction of alexidine and sodium hypochlorite. J Endod. 2012;38(1):112-6.

PMid:22152633
18. Mortenson D, Sadilek M, Flake NM, Paranjpe A, Heling I, Johnson JD, et al. The effect of using an alternative irrigant between sodium hypochlorite and chlorhexidine to prevent the formation of para-chloroaniline within the root canal system. Int Endod J. 2012;45(9):878-82. https://doi. org/10.1111/j.1365-2591.2012.02048.x PMid:22486894

19. James MN, Williams GJ. A refinement of the crystal structure of maleic acid. Acta Crystallogr. 1974;B30:1249-75.

20. MohammadiZ,ShalaviS, JafarzadehH.Ethylenediaminetetraacetic acid in endodontics. Eur J Dent. 2013;7(Suppl 1):S135-42. https:// doi.org/10.4103/1305-7456.119091

PMid:24966721

21. Prabhu SG, Rahim N, Bhat KS, Mathew J. Comparison of removal of endodontic smear layer using sodium hypochlorite, EDTA and different concentrations of maleic acid: A SEM study. Endodontology. 2003;15:20-5.

22. Ballal NV, Kundabala M, Bhat S, Rao N, Rao BS. A comparative in vitro evaluation of cytotoxic effects of EDTA and maleic acid: Root canal irrigants. Oral Surg Oral Med Oral Pathol Oral Radiol Endod. 2009;108(4):633-8. https://doi.org/10.1016/j. tripleo.2009.05.039 PMid: 19716720

23. Ballal NV, Moorkoth SM, Kundabala M, Bhat S, Hussen SS, Pathak S. Evaluation of chemical interactions of maleic acid with sodium hypochlorite and chlorhexidine gluconate. J Endod. 2011;37(10):1402-5. https://doi.org/10.1016/j.joen.2011.06.027

24. Rossi-Fedele G, Doğramaci EJ, Guastalli AR, Steier L, de Figueiredo JA. Antagonistic interactions between sodium hypochlorite, chlorhexidine, EDTA, and citric acid. J Endod. 2012;38(4):426-31. https://doi.org/10.1016/j.joen.2012.01.006 PMid:22414823

25. Jain K, Agarwal P, Jain S, Seal M, Adlakha T. Alexidine versus chlorhexidine for endodontic irrigation with sodium hypochlorite. Eur J Dent. 2018;12(3):398-402. https://doi.org/10.4103/ejd. ejd_180_17 PMid:30147406 